\title{
MODIFICATION OF POLYPROPYLENE MEMBRANES BY ION IMPLANTATION
}

\author{
Karolina Kotra-Konicka*1, Joanna Kalbarczyk ${ }^{2}$, Jakub M. Gac ${ }^{1}$ \\ ${ }^{1}$ Warsaw University of Technology, Faculty of Chemical and Process Engineering, \\ ul. Warynskiego 1, 00-645 Warsaw, Poland \\ ${ }^{2}$ Automotive Industry Institute, ul. Jagiellońska 55, 03-301 Warsaw, Poland
}

\begin{abstract}
The influence of ion implantation on the structure and properties of polymers is a very complex issue. Many physical and chemical processes taking place during ion bombardment must be taken into consideration. The complexity of the process may exert both positive and negative influence on the structure of the material. The goal of this paper is to investigate the influence of $\mathrm{H}^{+}, \mathrm{He}^{+}$and $\mathrm{Ar}^{+}$ ion implantation on the properties of polypropylene membranes used in filtration processes and in consequence on fouling phenomena. It has appeared that the ion bombardment caused the chemical modification of membranes which has led to decrease of hydrophobicity. The increase of protein adsorption on membrane surface has also been observed.
\end{abstract}

Keywords: ion implantation; polymer membranes; membrane separation; polymer surface modification

\section{INTRODUCTION}

Ion implantation has found widespread application in the field of material engineering, beginning from the metal surface implantation for hardening and mechanical properties improving (Conrad et al., 1987), through doping of semiconductor materials (Pearton, 1991) and, which concerns the following paper, polymer surface ion implantation (Kondyurin et al., 2008; Pieczyńska et al., 2011). The last issue has attracted a lot of attention recently due to improvement of mechanical properties of polymers (Popok, 2012). Another possible effect of ion bombardment, depending on the process parameters, may be the change of polymer optical or electrical properties, e.g. decrease of optical band gap energy and significant (about ten orders of magnitude) diminution of electrical resistance (Goyal et al., 2012; Resta et al., 2014). It may be expected that ion bombardment may also find the application in modification of polymer membranes to change their hydrophilicity and thus improve their anti-fouling properties.

The membrane separation methods (Arunima et al., 2009; Osada et al., 1992; Ulbricht, 2006) have been widely used recently in many branches of industry, e.g. chemical industry, food industry, environmental protection and many others. The main idea of these methods is to use the polymer (or, sometimes, ceramic or metal) membrane as a medium which allows some substances to pass while stops some others. The main advantage of this group of method is the possibility of separating very small compounds of the feed solution, e.g. colloidal particles, bacteria, macromolecules or even single ions. The serious problem concerning the membrane separation is a phenomenon known as membrane fouling. It consists in adhesion of feed solution compounds (particles or macromolecules) to membranes and thus blocking of the membrane surface (Chang et al., 1995; Quasirani et al., 2011). 
That leads to the reduction of permeate flux and slowing down the filtration. There are many methods of the elimination or reduction of fouling. The most popular seem to be modifications of membrane surface i.e. by coating with water-soluble polymers, charged surfactants onto the membrane surface (Jonsson et al., 1991), or other hydrophilic polymers on the membrane (Stengaard, 1998) or grafting monomers to membranes by electron beam irradiation (He et al, 2009; Kim et al., 1991; Ma et al., 2000). Modification of membrane surface may not only be conducive to reduction of fouling but may also lead to other changes of membrane properties. E.g. grafting membrane surface with polyelectrolytes results in $\mathrm{pH}$-dependent permeability of such membranes (Gac et al., 2015; Ramirez et al., 2003). On the other hand, modification of membrane surface with metal nanoparticles results in antibacterial properties of membranes and thus biofouling reduction (Basri et al., 2011). The ion implantation of the membrane surface also might transpire as a useful method of modifying surface properties to prevent fouling.

The aim of this paper is to present the results of investigations of polymer membrane modification using the ion implantation method. We present the change of morphology (porosity) of membranes, their hydrophilicity and the tendency to absorption of proteins being an effect of ion bombardment. We also investigate the dependence of these effects on the kind of ions used in ion bombardment.

The characteristic parameters of implantation are the energy and ion dose of the particular process (Garcia et al., 2011). Because of the sensitivity of polypropylene membranes the energy could not be too high and the dose was selected experimentally. During the implantation the ion beam radiation modifies the chemical composition and related physical properties of the polymer (Changsheng et al., 2013; Dworecki et al., 2004; Nenadović et al., 2012; Seunghee et al., 1997; Singh et al., 2014; Turos et al., 2003). These modifications depend on the ion beam energy and ion dose (Nenadović et al., 2012). The effect of the radiation resulting from electronic excitation, nuclear collision and carbonization of implanted surface taking place when energy is released is main-chain scission and cross-linking which causes modification of polymer properties - adhesion, wetting, biological compatibility etc.

Electronic excitation leads to ionization of polymer molecules and in consequence to radical formation. Nuclear collision results in breakage of chemical bonds (Sviridov, 2003). Carbon structures, which are forming during the process, cause significant hardness increase because of reinforcement of the polymer surface.

Modification of wettability results either from the oxidation of ion-implanted polymer or from the changes in initial concentration of polar groups. The formation of surface pores additionally increases wettability making the polymer properties superhydrophilic (Sviridov, 2003).

The efficacy of ion bombardment in case of increasing the hydrophilicity and improving anti-fouling properties of some polymers has been already proved (Manso et al., 2005; Pieczyńska et al., 2011). The aim of the following thesis is to analyze the influence of ion $\left(\mathrm{H}^{+}, \mathrm{He}^{+}, \mathrm{Ar}^{+}\right)$implantation at specific process conditions on the anti-fouling properties of polypropylene membranes.

\section{MATERIALS AND METHODS}

Polypropylene (PP) capillary membranes Acurel PP V8/2HF with inner diameter of $1.8 \mathrm{~mm}$ and wall thickness $0.8 \mathrm{~mm}$ were purchased from MEMBRANA ${ }^{\circledR}$. Polypropylene is a thermoplastic polymer used in a wide variety of applications. Modified membranes can be used in a lot of applications where membrane fouling is a serious problem.

Capillary membranes are widely used commercially. That is the reason why this type of membranes was chosen. Moreover, the flow during adsorption test is more relevant than in case of flat sheet membranes. 
The process of high energy ion beam bombardment was carried out using a Balzers MPB 202RP implanter. The scheme of the device is presented in Fig. 1. The implanter contains an ion source, an accelerator and a target chamber. The membrane was placed into the chamber and the ion beam passes through the magnetic separator and the scanner which ensures a homogeneous bombardment of a relatively large area. To improve the homogeneity of the modification of the whole membrane, the sample was rotated during the ion bombardment. Produced ions were implanted to the membrane and changed its structure.

The incident energy of implantation and the ion dose were selected experimentally to achieve the most advantageous properties of membranes. The values of above mentioned parameters were equal, respectively, $30 \mathrm{keV}$ and $10^{13}$ ions $/ \mathrm{cm}^{2}$.

Changes in membrane surface morphology were characterized by means of scanning electron microscopy (Hitachi SU8000). Before analysis, membranes were dried in room temperature for at least $24 \mathrm{~h}$.

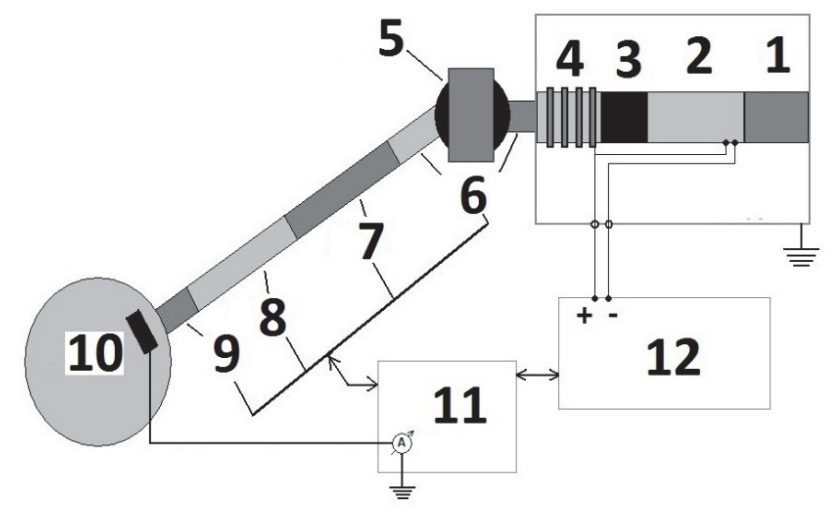

Fig. 1. Scheme of the ion implanter;

1 - gas feed, 2 - ion source power supply, 3 - ion source, 4 - accelerator, 5 - magnetic mass separator, 6 - ion beam focusing, 7- X-Y scanner, 8 - deflector $\left(7^{\circ}\right), 9$ - ion beam diagnostics, 10 - target chamber,

11 - control and diagnostics, 12 - high voltage power supply $(0-200 \mathrm{kV})$

To investigate the chemical structure of unmodified and modified membranes, Nicolet 6700 FT-IR was used. Each spectrum was obtained by cumulating 32 scans at a resolution of $4 \mathrm{~cm}^{-1}$.

Membrane hydrophilicity was studied by measuring contact angles (Krüss Processor Tensiometer K12) of the membranes at $25^{\circ} \mathrm{C}$. PP (native and modified) capillary membranes were immersed into water and tested 5 times. The average of measured values was taken as a contact angle of membrane with respect to water. The Wilhelmy method was used to determine surface tension of water and contact angle.

To investigate the ability of modified membranes to absorb proteins, they were immersed into Bovine Serum Albumin (BSA) solution (concentration equal to $1 \mathrm{~g} / \mathrm{L}$ ) for 24 hours. Temperature was kept at $20^{\circ} \mathrm{C}$. The $\mathrm{pH}$ was adjusted to 7.2. After 24 hours membranes were removed from a test-tube. The amount of protein from test tube was measured with a spectrophotometer at $280 \mathrm{~nm}$. The difference of protein content in samples before and after adsorption was recalculated to the amount of BSA adsorbed on the membrane.

\section{RESULTS AND DISCUSSION}

Membrane morphologies were shown in SEM images as presented in Fig. 2. It was found that the SEM images of the membrane structure modified with three different ions were changing with atomic mass. 
Membrane modified by hydrogen ions (Fig. 2b) did not differ significantly from unmodified membrane (2a). The modification with the heaviest argon ions (Fig. 2d) resulted in the biggest pores. It is also interesting that implantation with helium ions (Fig. 2c) caused polypropylene melting and pore decreasing.

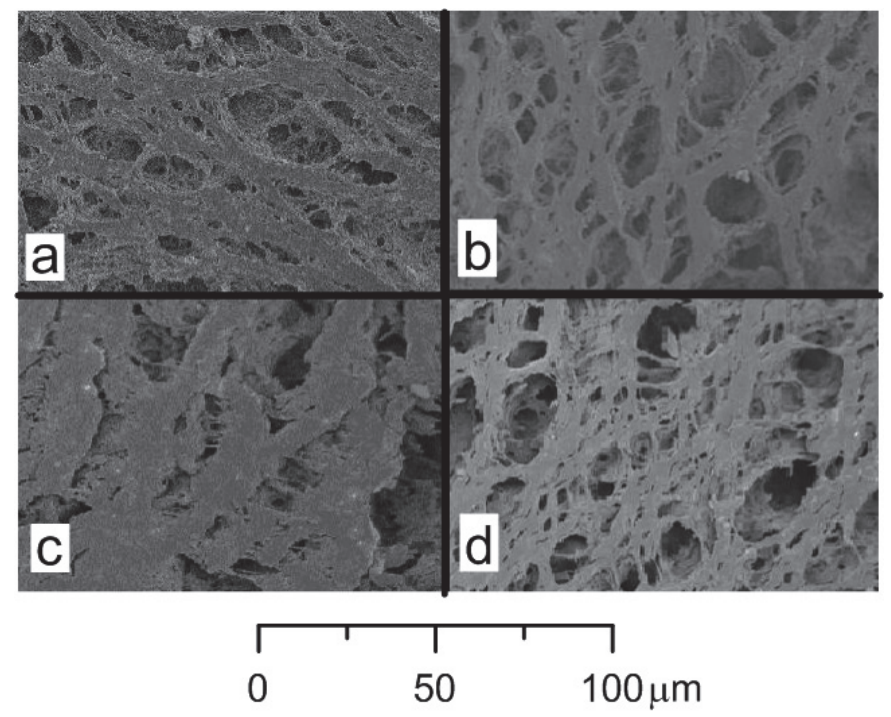

Fig. 2. SEM images of top surface of unmodified membrane (a), implantation with hydrogen ions (b), implantation with helium ions (c), and implantation ions (d)

The effect of increasing pore dimension was investigated numerically by means of numerical analysis of SEM pictures. First, the SEM picture of every membrane was binarised with the threshold set at maximum of the image histogram. As a result, it was possible to identify pores and inter-pore areas. The pores were then approximated by the ellipses and finally their mean radii were computed as an arithmetic mean value of semi-major and semi-minor axes. Finally, the result of this procedure was averaged over five different pictures of every membrane.

Figure 3 presents the histogram of mean pore radii for three membranes: unmodified and modified with $\mathrm{He}^{+}$and $\mathrm{Ar}^{+}$ions. The case of membrane modified with $\mathrm{H}^{+}$ions has not been shown since it is very similar to the case of $\mathrm{Ar}^{+}$. First, we recognize that the total density of pores was significantly lower for membranes after ion bombardment compared to that of unmodified membranes. This tendency is connected with the cross-linking effect analysed below.

After ion bombardment appeared pores with a significantly greater radius than that in original PP membrane. Moreover, while the surface density of pores with diameter less than $2.5 \mu \mathrm{m}$ was higher for unmodified membranes, the density of greater pores was higher for membranes after bombardment. Following on form that, the mean pore radius was higher for the modified membranes. Fig. 4 presents the mean pore radius for the original and three modified membranes. The mean pore radius for all the modified membranes is significantly greater than that of the unmodified one but for the membrane treated with $\mathrm{He}^{+}$ions it is a little bit smaller than that of those modified with $\mathrm{H}^{+}$and $\mathrm{Ar}^{+}$ions.

The pore radii obtained by means of image analysis for PP membranes are significantly greater than those provided by the producer. The reason is that the last ones are obtained by means of the bubble point method so they represent the radius of the thinnest narrowing of the pore. Our method gives the radius of the inlet of the pore. While we consider the adsorption of proteins - not permeation - this radius seems to be more suitable for further analysis. 


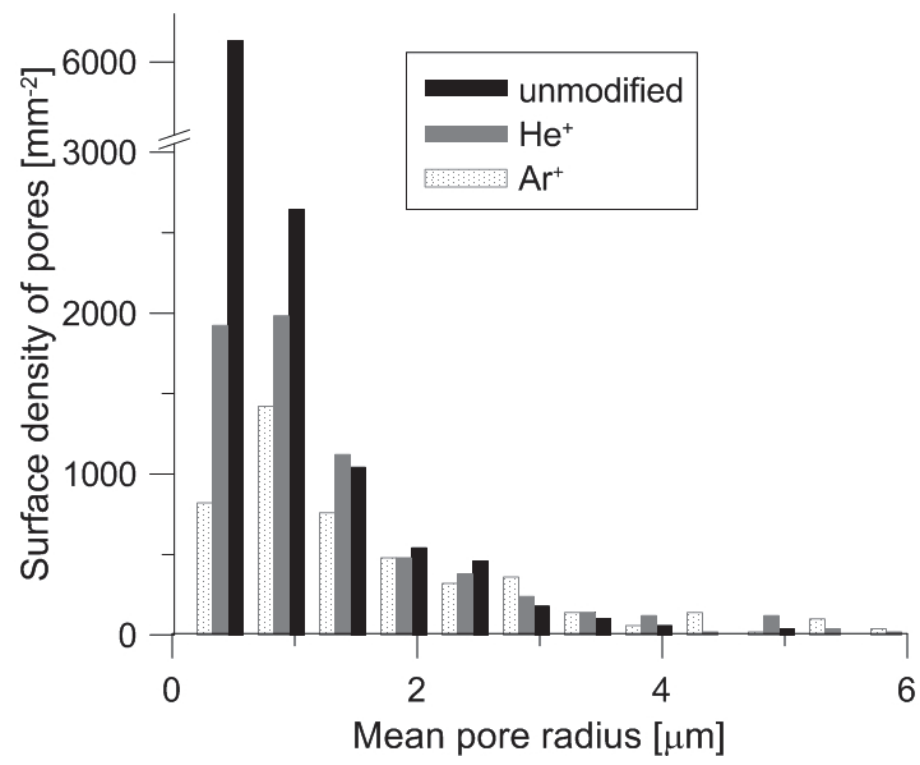

Fig. 3. The histogram of the pore radii for unmodified PP membrane and the membranes after bombardment with $\mathrm{He}^{+}$and $\mathrm{Ar}^{+}$ions

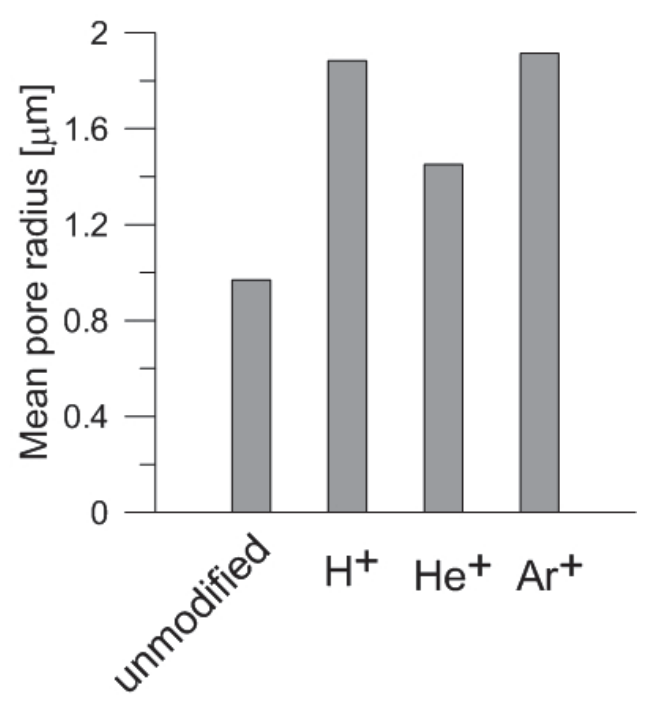

Fig. 4. Mean pore radius for original PP membrane and membranes after ion bombardment

FT-IR spectra of investigated membranes, presented in Fig. 5, show changes in the polymer structure appearing as an effect of ion bombardment. At the wave number equal to $3200-3500 \mathrm{~cm}^{-1}$ the rise of relatively weak maximum corresponding to hydroxyl groups can be recognized. Other peaks which appear in the spectra of modified membranes correspond to methyl groups (wave number 2800-3000 $\left.\mathrm{cm}^{-1}\right)$ or carbon-carbon bonds $\left(1600-1680 \mathrm{~cm}^{-1}\right)$. The appearance or growth of the number of these groups was the evidence that as an effect of ion bombardment the cross-linking and graphitization of outer layer of the PP membranes took place.

The height of the peaks depends on the type of the ion. The highest peaks are observed for $\mathrm{He}^{+}$ implantation which means that in this case the strongest modification of the membrane surface took place. 


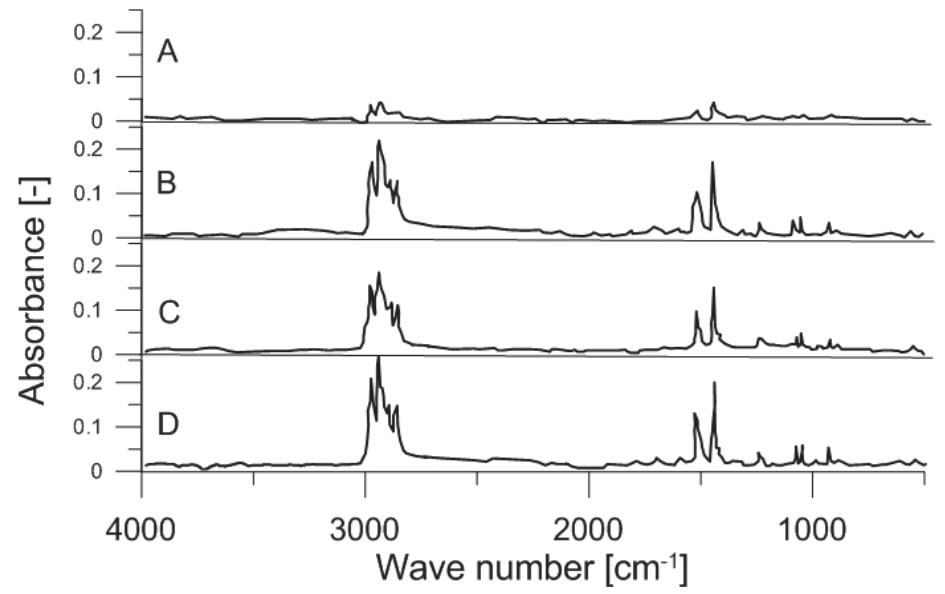

Fig. 5. FT-IR spectra for unmodified membrane (A) and $\mathrm{Ar}^{+}(\mathrm{B}), \mathrm{H}^{+}(\mathrm{C})$ and $\mathrm{He}^{+}(\mathrm{D})$ ion implantation

The contact angle measurement for water is one of the methods for characterization of the hydrophilic properties of the membrane surface. Hydrophilic surface gives a low contact angle (less than $90^{\circ}$ ), while a hydrophobic surface provides a high contact angle. The results of contact angle measurement showed that the base membrane had a contact angle of $134.9 \pm 5^{\circ}$. For the membranes modified with $\mathrm{Ar}^{+}, \mathrm{He}^{+}$and $\mathrm{H}^{+}$ions the contact angles was equal to $110.4 \pm 8^{\circ}, 114.6 \pm 2^{\circ}$ and $115.2 \pm 17^{\circ}$, respectively (see Fig. 6). Though ion implantation seems to cause a slight hydrophilicity increase of the modified membranes, the change has no practical meaning. Moreover, the difference between the measured values of the contact angle of modified and unmodified membranes (up to $20^{\circ}$ ) is nearly equal to measurement errors $\left(17^{\circ}\right.$ for $\mathrm{H}^{+}$ions). Concluding, one may state that the modification did not cause the change of hydrophobicity of membranes.

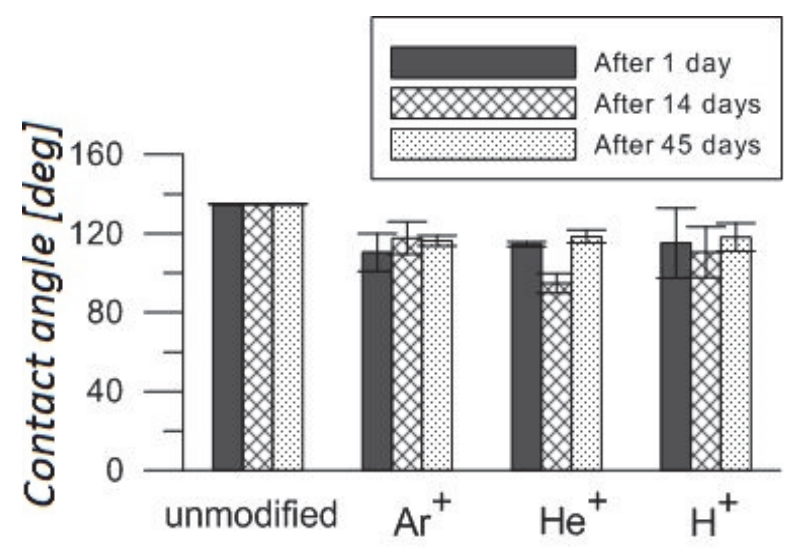

Fig. 6. Contact angle measurements obtained for unmodified samples and those implanted with $\mathrm{Ar}^{+}, \mathrm{He}^{+}$ and $\mathrm{H}^{+}$ions. Measurements were taken after 1, 14 and 45 days after ion implantation

Fig. 7 shows the results of static BSA adsorption on the membrane surface at $\mathrm{pH}$ 7.2. The results show that the base membrane adsorbed $13.8 \pm 2 \mathrm{mg} / \mathrm{cm}^{2}$. For the membranes modified with $\mathrm{Ar}^{+}, \mathrm{He}^{+}$and $\mathrm{H}^{+}$ ions the BSA adsorption was $24.2 \pm 3 \mathrm{mg} / \mathrm{cm}^{2}, 22.4 \pm 3 \mathrm{mg} / \mathrm{cm}^{2}$ and $24.4 \pm 4 \mathrm{mg} / \mathrm{cm}^{2}$, respectively. The unmodified PP membrane had a lower amount of BSA adsorption than the modified membranes despite the higher hydrophobicity of the unmodified membrane.

The improvement of static BSA adsorption may be explained as follows. Ion bombardment leads not only to the change of chemical composition of the membrane surface but also to the change in the morphology of this surface. As a result of ion bombardment the mean size of membrane pores increases. That leads to the increase of the surface available for BSA adsorption and, in consequence, to increase of the amount of adsorbed protein (as presented in Fig. 8) and thus the decrease of hydrophobicity. We have also noticed that the increase of mean pore radius for $\mathrm{He}^{+}$ions bombardment 
was not as big as that for the two others. That is the reason why the increase of the amount of BSA adsorbed on this membrane was little bit smaller.

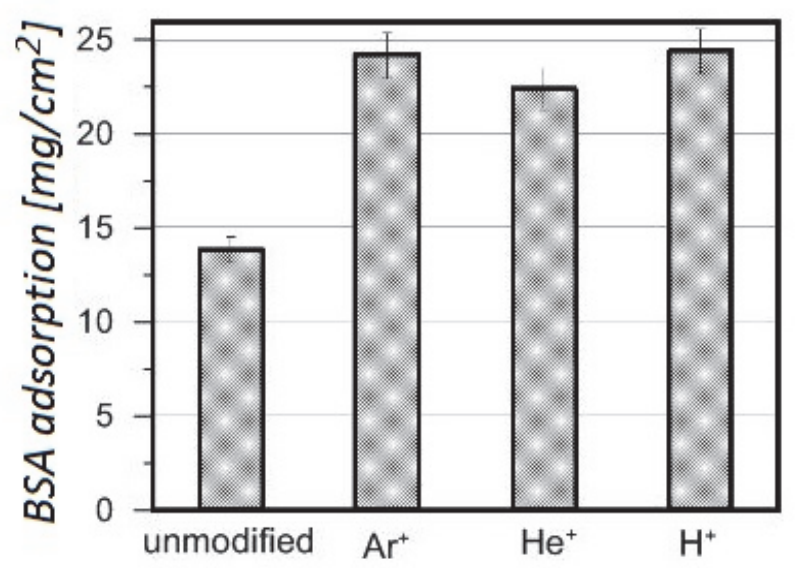

Fig. 7. The amount of BSA adsorbed on unmodified membrane and membranes modified with $\mathrm{Ar}^{+}, \mathrm{He}^{+}$ and $\mathrm{H}^{+}$ions

a)

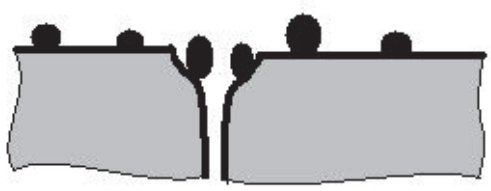

b)

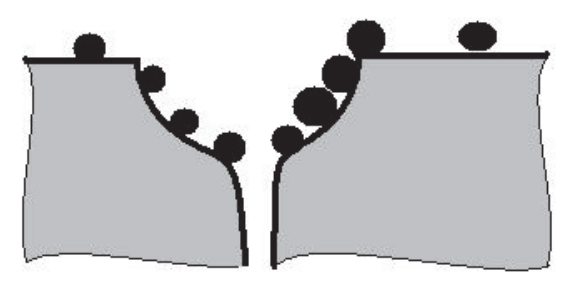

Fig. 8. Mechanism of BSA adsorption on the surface of a porous membrane. A smaller pore radius (a) results in lower adsorption capacity than the bigger one (b)

\section{CONCLUSIONS}

It can be concluded that the type of ion source has influence on pore size and membrane hydrophilicity after modification (with increasing mass the impact was stronger). $\mathrm{He}^{+}$ion implantation caused melting of the membrane structure - the energy of the process in this case was probably too high. New peaks in FTIR spectra signalized modification of the polypropylene membrane chemical structure. The level of peaks was also related to the atomic mass of ion source.

The protein adsorption after ion implantation was is higher. It may be explained as a result of a change of pore diameter distribution. These results allow to expect that the fouling of modified membranes during protein separation will be greater than that in a case of unmodified ones.

For a better understanding of the process and its influence on the polypropylene membrane structure it is necessary to conduct experiments with an extended range of process energies and doses. Research can be also performed for other ion sources to obtain more specific properties of the modified material.

\section{REFERENCES}

Arunima S., Bijay T.P., Mahendra K., Vinod S K., 2009. Membrane-based techniques for the separation and purification of proteins: An overview. Adv. Colloid Interface Sci., 145, 1-22. DOI: 10.1016/j.cis.2008.07.004. 
Basri H., Ismail A.F., Aziz M. 2011, Polyethersulfone (PES) ultrafiltration (UF) membranes loaded with silver nitrate for bacteria removal. Membr. Water Treat., 2, 25-37. DOI: 10.12989/mwt.2011.2.1.025.

Chang D.J., Hsu F.C., Hwang S.J., 1995. Steady-state permeate flux of cross-flow microfiltration. J. Membr. Sci., 98, 97-106. DOI: 10.1590/S0104-66322013000100019.

Changsheng Z., Jimin X., Fen R., Shudong S., 2013. Modification of polyethersulfone membranes - A review of methods. Prog. Mater. Sci., 58, 76-150. DOI: 10.1016/j.pmatsci.2012.07.002.

Conrad J.R., Radtke J.L., Dodd R.A., Worzala F.J., Tran N.C., 1987. Plasma source ion implantation technique for surface modification of materials. J. Appl. Phys., 62, 4591-4596. DOI: 10.1063/1.339055.

Dworecki K., Drabik M., Hesegawa T., Wąsik S., 2004. Modification of polymer membranes by ion implantation. Nucl. Instrum. Methods Phys. Res., Sect. B, 225, 483-488. DOI: 10.1016/S0168-583X(01)00779-0.

Gac J.M., Bojarska M., Stępniewska I., Piątkiewicz W., Gradoń L., 2015. Permeability of pH-sensitive membranes grafted by Fenton-type reaction: An experimental and modeling study. Membr. Water Treat., 6 , 411-422. DOI: 10.12989/mwt.2015.6.5.411.

Garcia J.A., Rodriguez R.J., 2011. Ion implantation techniques for non-electronic applications. Vacuum, 85, 1125-1129. DOI: 10.1016/j.vacuum.2010.12.024.

Goyal P.K., Kumar V., Gupta R., Mahendia S., Khokhar A., Kumar S., 2012. Modification of polycarbonate surface by $\mathrm{Ar}^{+}$ion implantation for various opto-electronic applications. Vacuum, 86, 1087-1091. DOI: 10.1016/j.vacuum.2011.10.007.

He D., Susanto H., Ulbricht M., 2009. Photo-irradiation for preparation, modification and stimulation of polymeric membranes. Progress Polymer Sci., 34, 62-98. DOI: 10.1016/j.progpolymsci.2008.08.004.

Jonsson A., Jonsson B., 1991. The influence of nonionic and ionic surfactants on hydrophobic and ultrafiltration membranes. J. Membrane Sci., 56, 49-76. DOI: 10.1016/0376-7388(91)85015-W.

Kim M., Saito K., Forusaki S., 1991. Water flux and protein adsorption of a hollow fiber modified with hydroxyl groups. J. Membrane Sci., 56, 289-302. DOI: 10.1016/S0376-7388(00)83039-2.

Kondyurin A, Bilek M., 2008. Ion beam treatment of polymers. Elsevier, UK.

Ma H. , Davis R.H., Bowman C.N., 2000. A novel sequential photoinduced living graft polymerization. Macromolecules, 33, 331-335. DOI: 10.1021/ma990821s.

Manso M., Valsesia A., Lejeune M., Gilliland D., Ceccone G., Rossi F., 2005. Tailoring surface properties of biomedical polymers by implantation of $\mathrm{Ar}$ and $\mathrm{He}$ ions. Acta Biomater., 1, 431-440. DOI: 10.1016/j.actbio.2005.03.003.

Nenadović M., Potočnik J., Ristić M., Štrbac S., Rakočević Z., 2012. Surface modification of polyethylene by $\mathrm{Ag}^{+}$and $\mathrm{Au}^{+}$ion implantation observed by phase imaging atomic force microscopy. Surf. Coat. Technol., 206, 4242-4248. DOI: 10.1016/j.surfcoat.2012.04.032.

Osada Y., Nakagawa T., 1992. Membrane Science and Technology. Marcel Dekker, Inc., New York.

Pearton S.J., 1991. Ion implantation doping and isolation of III-V semiconductors. Nucl. Instrum. Methods Phys. Res., Sect. B, 59, 970-977. DOI: 10.1016/0168-583X(91)95744-X.

Pieczyńska D., Ostaszewska U., Bieliński D.M., Jagielski J., 2011. Modification of polymers with the application of ion beam bombardment. Part I. History, recent developments and perspectives for development. Polimery, 56, 439-51.

Popok V.N., 2012. Ion implantation of polymers: Formation of nanoparticulate materials. Rev. Adv. Mater. Sci., $30,1-26$.

Quasirani T.M., Samhaber W.M., 2011. Impact of gas bubbling and backflushing on fouling control and membrane cleaning. Desalination, 266, 154-161. DOI: 10.1016/j.desal.2010.08.019.

Rabe M., Verdes D., Seeger S., 2009. Surface-induced spreading phenomenon of protein clusters. Soft Matter., 5, 1039-1047. DOI: 10.1039/B814053G.

Rabe M., Verdes D., Seeger S., 2011. Understanding protein adsorption phenomena at solid surfaces. $A d v$. Colloid Interface Sci., 162, 87-106. DOI: 10.1016/j.cis.2010.12.007.

Ramírez P., Mafé S., Alcaraz A., Cervera J., 2003. Modeling of pH-switchable ion transport and selectivity in nanopore membranes with fixed charges. J. Phys. Chem. B, 107, 13178-13187. DOI: 10.1021/jp035778w.

Resta, V., Quarta G., Farella I., Maruccio L., Cola A., Calcagnile L., 2014. Comparative study of metal and nonmetal ion implantation in polymers: Optical and electrical properties. Nucl. Instrum. Methods Phys. Res., Sect. B, 331, 168-71. DOI: 10.1016/j.nimb.2013.11.038. 
Seunghee H., Yeonhee L., Haidong K., Gon-ho K., Junghye L., Jung-Hyeon Y., Gunwoo K., 1997. Polymer surface modification by plasma source ion implantation. Surf. Coat. Technol., 93, 261-4. DOI: 10.1016/S02578972(97)00057-1.

Singh P., Kumar S., Prasad R., Kumar R., 2014. Study of physical and chemical modifications induced by 50 $\mathrm{MeV} \mathrm{Li}^{3+}$ ion beam in polymers. Radiat. Phys. Chem., 94, 54-57. DOI: 10.1016/j.radphyschem.2013.07.008.

Stengaard F.F., 1988. Characteristics and performance of new types of ultrafiltration membranes with chemically modified surfaces. Desalination, 70, 207-224. DOI:10.1016/0011-9164(88)85055-0.

Sviridov D.V., 2003. Ion implantation in polymers: Chemical aspects. Chemical problems of the development of new materials and technologies, Collection of papers, 88-106.

Turos A., Jagielski J., Piątkowska A., Bieliński D., Ślusarski L., Madi N. K., 2003. Ion beam modification of surface properties of polyethylene. Vacuum, 70, 201-206. DOI: 10.1016/S0042-207X(02)00643-7.

Ulbricht M., 2006. Advanced functional polymer membranes. Polymer, 47, 2217-2262. DOI: 10.1016/j.polymer.2006.01.084.

Received 12 June 2015

Received in revised form 24 April 2016

Accepted 27 April 2016 